\title{
Variation of morphological and chemical properties of three varieties of jute stick
}

\author{
M. Mostafizur Rahman ${ }^{1 *}$, S. Siddiqua ${ }^{2}$, F. Akter ${ }^{2}$, M. Sarwar Jahan ${ }^{1}$ and M. A. Quaiyyum ${ }^{2}$

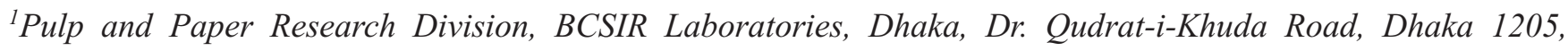 \\ Bangladesh \\ ${ }^{2}$ Department of Applied Chemistry and Chemical Engineering, University of Dhaka, Dhaka-1000,Bangladesh
}

\begin{abstract}
Pulp property of a lignocellulosic material depends upon its morphological characteristics and chemical constituents it. Shabuj Pat (CVL1) variety from Corchorus capsularis and BJRI Tossa Pat 4 (O-72) and BJRI Tossa Pat 5 (O-795) varieties from Corchorus olitorius of jute are mostly grown in Bangladesh. This study deals on morphological and chemical properties of these three varieties of jute stick to assess their suitability for pulp production. The results were significantly differed among the varieties and within the variety. The $\alpha$-cellulose content was almost the same in the variety of CVL-1 and O-795. In the same variety, the middle portion contained the largest amount of alpha-cellulose and the top portion contained the lowest. Klason lignin content varied from 24.2 to $26.8 \%$. Fibre length was significantly same for all the three jute sticks but the width and slenderness ratios were different. Pulp yield in soda anthraquinone process was nearly the same in all these varieties around $44 \%$ at kappa number 15 .
\end{abstract}

Keywords: Jute stick; Species variation; Chemical properties; Morphological properties

\section{Introduction}

Ascending rate of demand of paper and descending rate of forest land in the South Asia could be an important driving force of considering annual plant and agricultural residues as a raw material for producing pulp for paper and other purposes. Jute is an important cash crop which is cultivated mainly for bast fiber. On extracting bast fiber, the core of jute plant is about 2.5 times on weight basis the core has no industrial use so to say. Previous study showed that the ?-cellulose content in jute stick was about $46 \%$, but fiber length was shorter (Jahan et al., 2004). The differences in morphological and chemical characteristics and pulpability of the bast (bark) fiber of jute at different positions,viz., the top, middle and bottom were studied by Jahan (Jahan et al., 2008). It was found that the fiber length at the middle part of the bark was longer than the top and bottom part. This trend was also observed by Shafi et al. (1993). The lignin content decreased and -cellulose content increased with increasing height from bottom to top (Jahan et al., 2008). Chemical composition and morphological properties of plant material are very crucial parameters for determining pulp yield and quality. Pulp from agricultural residue produces uniform sheet with good printability and smoothness and improved opacity (Alcaide et al., 1991). Natural fibers are not only used to produce pulp for paper making but also have the potential to be applied a reinforcement material for biodegradable composite. Dhaincha (Sesbania aculeata) stalk is similar to jute stick to produce pulp with properties like hardwood in the point of view of fiber length and mechanical properties. The chemical and morphological properties of dhaincha vary with the harvesting age, which affect pulping and pulp properties (Jahan et al., 2009). Cotton stalk is another agricultural waste similar to jute stalk and produce good quality pulp in chemical and semi-chemical processes (Pandey and Shaikh, 1987). There are three varieties of jute cultivated most in Bangladesh. Therefore jute stick that remains as the leftover has the possibility of making paper grade pulp as well as dissolving pulp. In this context the study of its morphological and chemical composition is warranted. In this article, chemical and morphological properties of three varieties of jute stick namely Shabuj Pat (CVL-1) variety from Corchorus capsularis and BJRI

*Corresponding author e-mail: mmrbcsir@yahoo.com 
Tossa Pat 4 (O-72) and BJRI Tossa Pat 5 (O-795) varieties from Corchorus olitorius (Samiul Haque et al., 2007).

\section{Materials and methods}

\section{Raw Material}

Three varieties of jute sticks of Shabuj Pat (CVL-1), BJRI Tossa Pat 4 ( O-72), BJRI Tossa Pat 5 ( O-795) were supplied by the Bangladesh Jute Research Institute (BJRI). The jute sticks were dried in sun and chopped by hand machine to 5$7 \mathrm{~cm}$ in length for subsequent morphological and chemical analysis and digestion for pulping. For chemical analysis, the plant was grounded in Willey Mill and screened to 40/60 mesh.

\section{Morphological and Chemical analysis}

Samples were macerated in a solution containg $1: 1 \mathrm{HNO}_{3}$ and $\mathrm{KClO}_{3}$ for $24 \mathrm{~h}$ for the measurements of fiber length and width. A drop of macerated sample was taken on a slide and dried to remove water. The slide was placed under an image analyzer, Labomed LX 400 equipped with software Digipro 4.0 for taking image to measure fiber length and width. Bulk density was measured using $50 \mathrm{~mL}$ picnometer.

The chemical compositions of three parts, the bottom, middle and top, were determined according to TAPPI test methods: extractives (T204 om88), water solubility (T207cm99), and Klason lignin (T211 om83). Holocellulose samples were prepared by treating extractives-free meal with $\mathrm{NaClO}_{2}$ solution (Browining 1967). The $\mathrm{pH}$ of the solution was maintained at 4 by adding $\mathrm{CH}_{3} \mathrm{COOH}-\mathrm{CH}_{3} \mathrm{COONa}$ buffer and the $\alpha$-cellulose content was determined by treating holocellulose with $17.5 \% \mathrm{NaOH}$ (T203 om 93). Ash content was determined using Nuive muffle furnace at $525^{\circ} \mathrm{C}$ according to $\mathrm{T} 211 \mathrm{om}-93$. The pentosans content was determined using the bromide/bromate method.

\section{Pulping}

Soda-anthraquinone (AQ) pulping was done in a 5L capacity thermostatically controlled electrically heated rotary digester. The active alkali was varied from $14-18 \%$ as $\mathrm{NaOH}$ of the sample on oven dried (OD) basis with the liquor ratio of $1: 5$. AQ was $0.1 \%$ the raw material. The cooking was continued for $60 \mathrm{~min}$ at the maximum temperature $\left(170^{\circ} \mathrm{C}\right)$. At the end of pulping, the pressure was released to atmospheric pressure and pulp was taken out from the digester, disintegrated and washed by continuous flow of water. Pulp yield was determined on the basis of OD raw material. Kappa number was determined in accordance with T 236 $\mathrm{cm}-85$. All pulps were beaten in a PFI mill to 1000 revolutions and handsheets of $60 \mathrm{~g} / \mathrm{m}^{2}$ were made in a Rapid Kothen Sheet Making Machine according to German Standard Methods DIN 106. The physical properties of handsheets were determined as per Tappi method T 220 sp96.

\section{Results and discussion}

\section{Morphological properties}

Fibre morphology is an important characteristic to evaluate lignocellulosic material for pulping. Statistical data of fibre length, width and their slenderness ratios of different parts of three variety of jute stick(CVL-1, O-72, O-795) are given in Tables I and II. Fibre dimensions greatly influence the pulp properties. It is obvious from and Table I that statistically there are no differences in fibre length among the three varieties of jute stick but fibre of CVL-1 is wider than the other two varieties. On the other hand, fibre dimensions are significantly different within the jute stick of each variety. The middle portion contains the longest fibre in each variety of jute stick which agree with Jahan et. al. (2008). Fibre length and fibre diameter of these varieties are short and thick. These are comparable with hard wood (Manzanares et al., 1997). Consequently the slenderness ratio is poor. This may produce pulp with lower tear resistance (Ververis et al.,

Table I. Fibre dimensions of three varieties of jute stick and their slenderness ratio

\begin{tabular}{lcccc}
\hline Parameter & $\begin{array}{c}\text { Shabuj Pat } \\
(\mathrm{CVL1})\end{array}$ & $\begin{array}{c}\text { BJRI } \\
\text { Tossa Pat 4 (O72) }\end{array}$ & $\begin{array}{c}\text { BJRI } \\
\text { Tossa Pat 5 (O795) }\end{array}$ & $\begin{array}{c}\text { Olive tree } \\
\text { (Ververis } \text { et al., 2004) }\end{array}$ \\
\hline Fibre Length(L), mm & $0.87 \pm 0.16^{\mathrm{a}}$ & $0.85 \pm 0.17^{\mathrm{a}}$ & $0.89 \pm 0.21^{\mathrm{a}}$ & $0.85 \pm 0.07$ \\
Fiber width(D), $\mu \mathrm{m}$ & $38.9 \pm 7.30^{\mathrm{a}}$ & $31.7 \pm 7.05^{\mathrm{b}}$ & $33.9 \pm 4.58 \mathrm{~b}^{\mathrm{b}}$ & $15.1 \pm 2.0$ \\
Slenderness ratio, L/D & 22.4 & 26.8 & 26.3 & \\
\hline
\end{tabular}

* Same letters mean the data do not differ significantly at $95 \%$ level of significance 

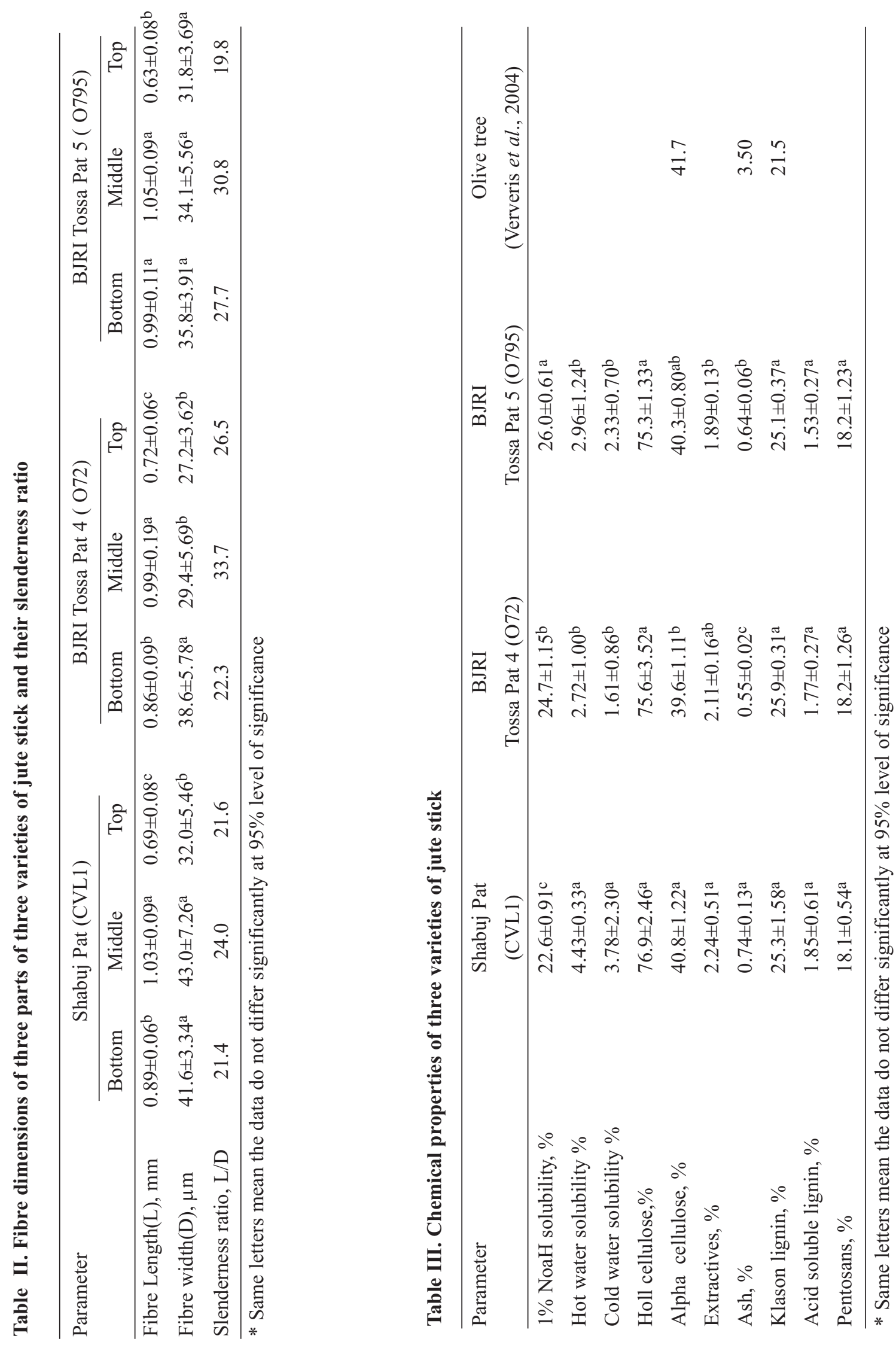
2004) due to less surface contact and fiber to fiber bonding (Ogbonnaya et al., 1997). So, long softwood pulp needs to be mixed with jute stick pulp to produce a wide range of paper grade pulp (Khristova et al., 1998).

CVL-1 is significantly different from the other two varieties O-72 and O-795 for fibre width. Table II reflects that middle portion of each variety had significantly better quality fibre than the bottom and the top with higher slenderness ratio. Coarse fibres adversely affect the bursting strength, tensile strength and Young's modulus (Kaur and Dutt, 2013; Munawar et al., 2007). Similar relationships were found in the case of flax fibre and jute fibre (Baley, 2002; Zhang et al., 1994).

\section{Chemical characterization}

Chemical properties are considerably different among varieties and different parts of jute stick (Tables III and IV). One percent sodium hydroxide solubility was highest in O795(26.0\%) and lowest in CVL-1(22.6\%). On the other hand, the top portion had the highest amount of $1 \%$ alkali solubility. It implies that the top portion contains low molecular mass carbohydrates and other alkali soluble materials (Kaur and Dutt, 2013). The middle portion of all the varieties contain lowest amount of $1 \%$ alkali solubility. Both hot and cold water solubility were highest in CVL-1 and lowest in O72. It means CVL -1 would require higher alkali dose to mitigate acidity due to water extractives (Kaur and Dutt, 2013). Middle part of all the varieties of jute stick contains lower water soluble material than all other parts. Difference between holocellulose and $\alpha$-cellulose represent hemicelluloses which are greatly responsible for giving overall strength of paper. The presence of hemicelluloses is significantly similar in CVL-1 and O-72, but different from O-795. Interestingly, holocelluloses were almost equal in all parts of CVL-1 and O-795. But significant difference exists within O-72. Alpha cellulose content more than $34 \%$ is considered as a promising raw material for pulp and paper manufacture (Nieschlag, 1960). All varieties of jute stick contained more than $38 \% \alpha$-cellulose. Therefore jute stick is a potential raw material for pulp production on this aspect.

Although all the varieties had no significant differences in $\alpha$ cellulose content among the varieties the middle part of each variety contains higher amount of $\alpha$-cellulose (Table IV). Such findings are in agreement with previous works (Jahan et al., 2008). Lignin content in jute sticks varied between $24.2 \%$ and $26.8 \%$. This is similar to hardwoods. Statistically

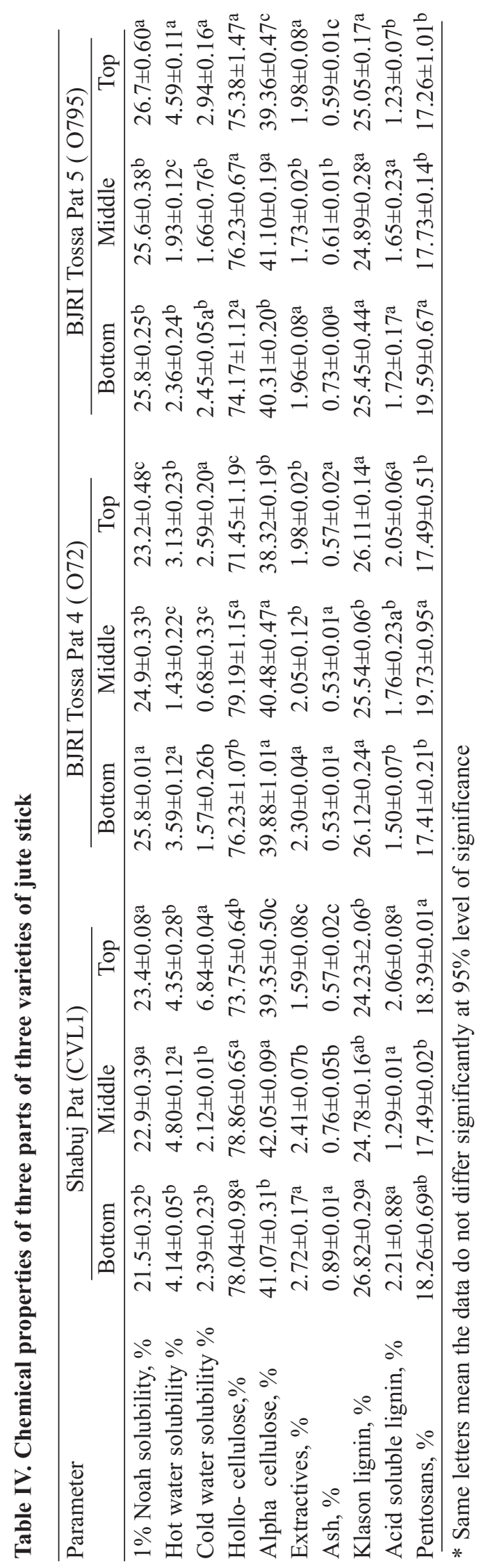


Table V. Pulp yield of jute stick

\begin{tabular}{|c|c|c|c|c|c|c|}
\hline \multirow[t]{2}{*}{ Alkali charge $(\%)$} & \multicolumn{2}{|c|}{ Shabuj Pat (CVL1) } & \multicolumn{2}{|c|}{ BJRI Tossa Pat 4 ( O72) } & \multicolumn{2}{|c|}{ BJRI Tossa Pat 5 ( O795) } \\
\hline & $\overline{\text { Pulp yield (\%) }}$ & Kappa number & Pulp yield (\%) & Kappa number & Pulp yield (\%) & Kappa number \\
\hline 14 & 45.2 & 24.0 & 45.0 & 25.3 & 45.6 & 23.4 \\
\hline 16 & 44.3 & 14.2 & 43.4 & 15.6 & 44.7 & 15.0 \\
\hline 18 & 42.9 & 14.0 & 41.8 & 15.2 & 43.1 & 13.4 \\
\hline
\end{tabular}

there is hardly any difference among the varieties in lignin content. However, it varied significantly within the variety. Lignin content decreased from the base to top along the stem. Neto et al. (1996) reported similar findings for kenaf and for reed. However, Nishimura et al. (2002) reported that the middle parts of kenaf stem contained higher amount of lignin. The same trend was reported for $\alpha$-cellulose by Neto et al. (1997) for kenaf and reed.

High ash content is undesirable in pulping raw material. Jute stick has lower ash content than other non-wood materials like sugarcane bagasse; sunflower, kenaf and cotton stalk (Kaur and Dutt, 2013). Among the varieties, O-72 contained the lowest amount of ash content, and CVL-1 had the highest amount (Table III). From It is clear that all the varieties contained the highest amount of ash at the bottom and the lowest at the top. High ash content especially silica causes serious problem during evaporation of black liquor and show poor drainage during paper making (Gratzl, 1989). It also significantly affects mechanical strength properties of paper (Kaur and Dutt, 2013).

\section{Pulping}

Jute sticks of three varieties were cooked by soda - AQ process. The results are presented in Table V. Pulp yield of the three varieties were of little difference in pulping process (Table V). Jute stick is wood-like non-wood material similar to mulberry plant, cotton stalk. But it needs low alkali charge and time for pulping mostly due to its less compactness. Pulp yield and kappa number decreased with increasing alkali charge. Kappa number dropped from 24 to 14 as the alkali charge increased from 14 to $16 \%$ with gradual decrease in pulp yield. Further, increase of alkali charge to $18 \%$, pulp yield decreased by 1.4-1.6\% without significant reduction of kappa number (Table IV). Therefore, $16 \%$ active alkali could be considered optimum at $1 \mathrm{~h}$ cooking time.

\section{Conclusion}

Morphological and chemical characteristics of three varieties of jute stick were examined. Although the difference of mor phological and chemical characteristics of the three varieties of jute stick were little, some properties like fibre width, alkali solubility, water solubility were significantly different. Of all the three varieties, shabuj pat (CVL-1) had the highest $\alpha$-cellulose. Middle part of all the varieties contains highest $\alpha$-cellulose and longer fibres

\section{Acknowledgement}

Authors are thankful to BCSIR for providing necessary fund to carry out the research.

\section{References}

Alcaide LJ, Baldovin FL and Parra IS (1991), Characterization of cellulose pulp from agricultural residues, Tappi J. 74: 217-221.

Baley C (2002), Analysis of the flax fibres tensile behaviour and analysis of the tensile stiffness increase. Compos. Part A, Appl. Sci. Manuf. 33: 939-948.

Blankenhorn PR, Bowersox TW, Kuklewski KM and Stimely GL (1985), Effects of rotation, site, and clone on the chemical composition of Populus hybrids, Wood Fiber Sci. 17: 351-360.

Clarke CR, Shaw MJ, Wessels AM and Jones WR (1999), Effect of differences in climate on growth, wood, and pulp properties of nine eucalypt species at two sites, TAPPIJ. 82: 89-99. US Patent No. 4,826,567.

Gratzl JS (1989), Process for the delignification of cellulosic substances by pretreating with a complexing agent followed by hydrogen peroxide. US Patent No. 4,826,567.

Jahan MS, Kanna GH, Mun SP and Chowdhury DAN (2008), Variations in chemical characteristics and pulpability within jute plant ( Chorcorus capsularis), Ind. Crop. Prod. 28: 199-205. doi:10.1016/j.indcrop. 2008. 02.013 
Jahan, MS and Mun SP (2004), Effect of tree age on the soda-anthraquinone pulping of nalita wood (Trema orientalisis), J. Ind. Eng. Chem. 10: 766-771.

Jahan MS, Mun SP and Rashid M (2004), Fiber dimensions and chemical properties of various nonwood materials and their suitability for paper production, J. Ktappi 36(5): 29-35.

Jahan MS, Sabina R, Tasmin B, Chowdhury DN, Noori A and Al-Maruf A (2009), Effect of harvesting age on the chemical and morphological properties of dhaincha (Sesbania aculeata) and its pulpability and bleachability, BioResources 4: 471-481.

Kaur H and Dut D (2013), Anatomical, morphological and chemical characterization of lignocellulose by-products of lemon and sofia grasses obtained after recuperation of essential oils by steam distillation, Cellul. Chem. Technol. 47, 83-94.

Khristova P, Bentcheva S and Karar I (1998), Soda-AQ pulp blends from kenaf and sunflower stalks, Bioresour. Technol. 66: 99-103.

Labosky, P, Bowersox TW and Blankenhorn PR (1983), Kraft pulp yields and paper properties obtained from first and second rotations of three hybrid poplar clones, Wood Fiber Sci. 15: 81-89.

Manzanares M, Tenorio JL and Ayerbe L (1997), Sowing time, cultivar, plant population and application of $\mathrm{N}$ fertilizer on Kenaf in Spain's central plateau, BiomassBioenergy 12: 263-271.

Miranda I and Pereira H (2002),. The variation of chemical composition and pulping yield with age and growth factors in young Eucalyptus globulus, Wood Fiber Sci. 34, 140-145.

Munawar SS, Umemura K and Kawai S (2007), Characterization of the morphological, physical, and mechanical properties of seven nonwood plant fiber bundles, J. Wood Sci. 53: 108-113.

Neto CP, Seca A, Fradinho D, Coimbra MA, Domingues F, Evtuguin D, Silvestre A and Cavaleiro JAS (1996), Chemical composition and structural features of the macromolecular components of Hibiscus cannabinus grown in Portugal, Ind. Crop. Prod. 5:189-196.
Neto CP, Seca A, Nunes AM, Coimbra MA, Domingues F, Evtuguin D, Silvestre A and Cavaleiro JAS (1997), Variations in chemical composition and structure of macromolecular components in different morphological regions and maturity stages of Arundo donax, Ind. Crop. Prod. 6 : 51-58.

Nishimura N, Izumi A and Kuroda K (2002), Structural characterization of kenaf lignin: differences among kenaf varieties, Ind. Crop. Prod. 15: 115-122.

Ogbonnaya CI, Roy-Macauley H, Nwalozie MC and Annerose DJM (1997), Physical and histochemical properties of kenaf (Hibiscus cannabinus L.) grown under water deficit on a sandy soil, Ind. Crop. Prod. 7: 9-18.

Pandey SN and Shaikh AJ (1987), Utilisation of cotton plant stalk for production of pulp and paper, Biol. Wastes 21: 63-70.

Samiul H, Selina Begum, RH, Sarker and Haseena Khan, (2007), Determining Genetic Diversity of Some Jute Varieties and Accessions Using RAPD Markers, Plant Tissue Cult. \& Biotech. 17(2): 183-191.

Shafi M, Akhtaruzzaman AFM and Mian AJ (1993), Puling of whole length jute with neutral silphite anthraqinone (NS-AQ) process, Holzforschung 47: 83-87.

Ververis C, Georghiou K, Christodoulakis N, Santas P and Santas R (2004), Fiber dimensions, lignin and cellulose content of various plant materials and their suitability for paper production, Ind. Crop. Prod. 19: 245-254.

Zhang M, Kawai S and Sasaki H (1994), Production and properties of composite fiberboard, 1: Influence of mixing ratio of jute/wood fiber on the properties of boards, J. Jpn. Wood Res. Soc. 40:816-823.

Received: 03 April 2016; Revised: 13 April 2016; Accepted: 24 April 2016. 